\title{
G protein-coupled receptor (GPR)40-dependent potentiation of insulin secretion in mouse islets is mediated by protein kinase D1
}

\author{
M. Ferdaoussi • V. Bergeron • B. Zarrouki • J. Kolic • \\ J. Cantley • J. Fielitz • E. N. Olson • M. Prentki • T. Biden • \\ P. E. MacDonald • V. Poitout
}

Received: 7 March 2012 / Accepted: 18 June 2012 /Published online: 22 July 2012

(C) Springer-Verlag 2012

\begin{abstract}
Aims/hypothesis Activation of the $\mathrm{G}$ protein-coupled receptor (GPR) 40 by long-chain fatty acids potentiates glucosestimulated insulin secretion (GSIS) from pancreatic beta cells, and GPR40 agonists are in clinical development for type 2 diabetes therapy. GPR40 couples to the G protein subunit $\mathrm{G} \alpha_{\mathrm{q} / 11}$ but the signalling cascade activated downstream is unknown. This study aimed to determine the mechanisms of GPR40-dependent potentiation of GSIS by fatty acids.

Methods Insulin secretion in response to glucose, oleate or diacylglycerol (DAG) was assessed in dynamic perifusions
\end{abstract}

Electronic supplementary material The online version of this article (doi:10.1007/s00125-012-2650-x) contains peer-reviewed but unedited supplementary material, which is available to authorised users.

M. Ferdaoussi · V. Bergeron · B. Zarrouki · M. Prentki •

V. Poitout $(\square)$

Montreal Diabetes Research Center, CRCHUM,

Technopole Angus,

2901 Rachel Est,

Montréal, QC, Canada H1W 4A4

e-mail: Vincent.poitout@umontreal.ca

M. Ferdaoussi $\cdot$ V. Bergeron $\cdot$ B. Zarrouki $\cdot$ V. Poitout

Department of Medicine, University of Montreal,

Montreal, QC, Canada

J. Kolic $\cdot$ P. E. MacDonald

Department of Pharmacology and the Alberta Diabetes Institute,

University of Alberta,

Edmonton, AB, Canada

J. Cantley $\cdot$ T. Biden

Garvan Institute of Medical Research,

St Vincent's Hospital,

Darlinghurst,

Sydney, NSW, Australia and static incubations in islets from wild-type (WT) and $\mathrm{Gpr}_{40} \mathrm{O}^{-/}$mice. Depolymerisation of filamentous actin (F-actin) was visualised by phalloidin staining and epifluorescence. Pharmacological and molecular approaches were used to ascertain the roles of protein kinase $\mathrm{D}$ (PKD) and protein kinase C delta in GPR40-mediated potentiation of GSIS.

Results Oleate potentiates the second phase of GSIS, and this effect is largely dependent upon GPR40. Accordingly, oleate induces rapid F-actin remodelling in WT but not in $\mathrm{Gpr} 40^{-/-}$ islets. Exogenous DAG potentiates GSIS in both WT and $\mathrm{Gpr}_{40} \mathrm{O}^{--}$islets. Oleate induces PKD phosphorylation at

\section{J. Fielitz}

Experimental and Clinical Research Center, a joint cooperation between the Charité Medical Faculty and the Max-Delbrück

Center for Molecular Medicine,

Berlin, Germany

J. Fielitz

Medical Department, Division of Cardiology, Charité University, Campus Virchow-Klinikum,

Berlin, Germany

E. N. Olson

Departments of Molecular Biology, Internal Medicine, and Pathology, University of Texas Southwestern Medical Center, Dallas, TX, USA

M. Prentki $\cdot$ V. Poitout

Departments of Nutrition and Biochemistry,

University of Montreal,

Montreal, QC, Canada 
residues Ser-744/748 and Ser-916 in WT but not $\mathrm{Gpr}_{40} 0^{-1-}$ islets. Importantly, oleate-induced F-actin depolymerisation and potentiation of GSIS are lost upon pharmacological inhibition of PKD1 or deletion of Prkd1.

Conclusions/interpretation We conclude that the signalling cascade downstream of GPR40 activation by fatty acids involves activation of PKD1, F-actin depolymerisation and potentiation of second-phase insulin secretion. These results provide important information on the mechanisms of action of GPR40, a novel drug target for type 2 diabetes.

Keywords Diacylglycerol · Filamentous actin - G proteincoupled receptor $\cdot$ GPR $40 \cdot$ Insulin secretion · Islet · Protein kinase $\mathrm{D} \cdot$ Type 2 diabetes

$\begin{array}{ll}\text { Abbreviations } \\ \text { DAG } & \text { Diacylglycerol } \\ \text { ER } & \text { Endoplasmic reticulum } \\ \text { F-actin } & \text { Filamentous actin } \\ \text { GPCR } & \text { G protein-coupled receptor } \\ \text { GPR40 } & \text { G protein-coupled receptor 40 } \\ \text { GSIS } & \text { Glucose-stimulated insulin secretion } \\ \text { IBMX } & \text { 3-Isobutyl-1-methylxanthine } \\ \text { IP3 } & \text { Inositol 1,4,5-trisphosphate } \\ \text { PKC } & \text { Protein kinase C } \\ \text { PKD } & \text { Protein kinase D } \\ \text { PLC } & \text { Phospholipase C } \\ \text { WT } & \text { Wild-type }\end{array}$

\section{Introduction}

Diabetes is reaching pandemic proportions throughout the world and is expected to affect over 550 million people worldwide in 2030 [1]. The most common form of the disease, type 2 diabetes, occurs when pancreatic beta cells are unable to secrete an adequate amount of insulin to compensate for peripheral insulin resistance [2]. Insulin secretion is regulated chiefly by glucose through intracellular metabolism of the sugar, and is additionally modulated by non-glucose secretagogues such as incretin hormones, fatty acids and muscarinic stimulation via $G$ protein-coupled receptors (GPCRs) [3]. Since activation of these receptors augments insulin secretion only when glucose levels are elevated, they can be targeted therapeutically to enhance insulin levels with minimal risks of iatrogenic hypoglycaemia. $\mathrm{G}$ protein-coupled receptor 40 (FFAR1/GPR40) is a GPCR activated by medium- to longchain fatty acids and predominantly found in pancreatic beta cells [4-6]. Deletion of Gpr40 markedly reduces the potentiation of glucose-induced insulin secretion (GSIS) by fatty acids both in vivo and in isolated islets [4, 7-9]. Conversely, both transgenic overexpression of Gpr40 in beta cells [10] and administration of GPR40 agonists enhance insulin secretion in rodents [11-13]. Importantly, we [7, 14] and others [15-17] have shown that GPR 40 does not mediate the lipotoxic effects of chronically elevated fatty acid levels on pancreatic beta cell function. Collectively, these observations provide a strong rationale for the development of GPR40 agonists for the treatment of type 2 diabetes. Indeed, the recently released results of a phase 2 clinical trial of the agonist compound TAK-875 showed very promising efficacy $[18,19]$.

Despite recent progress made towards the development of GPR40-based drugs for type 2 diabetes, surprisingly little is known regarding the mechanism of action of the receptor. The insensitivity of GPR40 signalling to pertussis toxin [20] and its sensitivity to pharmacological inhibitors of the $G$ protein subunit $\mathrm{G}_{\alpha \mathrm{q} / 11}$ and phospholipase C (PLC) $[5,7]$ suggest that GPR40 is coupled to $\mathrm{G} \alpha_{\mathrm{q} / 11}$, although coupling via $G_{\alpha i}$ has also been suggested [20]. $G \alpha_{q / 11}$ typically signals through PLC-mediated hydrolysis of membrane phospholipids and the generation of inositol 1,4,5-trisphosphate (IP3) and diacylglycerol (DAG). Although IP3 levels in islets increase in response to fatty acids in a GPR40dependent manner [8], the functional importance of endoplasmic reticulum (ER) $\mathrm{Ca}^{2+}$ stores remains unclear [21] and, to our knowledge, the contribution of the DAG branch of the pathway to GPR40 signalling has not been tested. In addition, the nature of the signalling kinase(s) activated downstream of GPR40 and which mediate the insulin secretory response to fatty acids remains unknown. As GPR40 agonists are under clinical development to become novel type 2 diabetes drugs, it is critical to better understand the signalling mechanisms of the receptor.

Therefore, this study aimed to determine: (1) the kinetics of the potentiation of GSIS by fatty acids via GPR 40 in isolated mouse islets; (2) the cellular events underlying this effect and (3) the signalling molecules activated downstream of GPR40 in the beta cell.

\section{Methods}

Reagents RPMI-1640 and FBS were from Invitrogen (Burlington, ON, Canada). Adenoviruses encoding IRES-GFP (Ad-GFP) and Cre-IRES-GFP (Ad-Cre) were kindly provided by J. Estall, Institut de Recherches Cliniques de Montreal, Montreal, QC, Canada. Antibodies against protein kinase D (PKD) (phospho-serine 744/748, phospho-serine 916 and total PKD1) were from Cell Signal (Pickering, ON, Canada). 1,2-Dioctanoyl-glycerol (8:0) was from Enzo Life Science (Brockville, ON, Canada). Oleic acid and 3-isobutyl-1-methylxanthine (IBMX) were from Sigma (St Louis, MO, USA). Rottlerin was from Calbiochem (Gibbstown, NJ, USA).

Islet isolation and cell culture Gpr40 $0^{-1-}$ mice, whole-body PKC $\delta$-null $\left(\mathrm{Prkcd}^{--}\right)$mice and mice bearing a protein kinase 
D1 allele flanked by Lox-P sites ( $\left.P r k d 1^{\text {flox/flox }}\right)$ were generated as respectively described [7, 22, 23]. Wild-type (WT) littermates were used as controls. Mouse islets were isolated by hand-picking after collagenase digestion of the pancreas as described [7], and maintained overnight in RPMI-1640 supplemented with $10 \%$ (wt/vol.) FBS, $100 \mathrm{U} / \mathrm{ml}$ penicillin-streptomycin and $11 \mathrm{mmol} / \mathrm{l}$ glucose. All procedures were approved by the institutional committee for the protection of animals at the Centre Hospitalier de l'Université de Montréal. The rat insulin-secreting cell line INS832/13 was cultured in RPMI1640 medium supplemented with $11 \mathrm{mmol} / 1$ glucose, 10\% (wt/vol.) FBS, $10 \mathrm{mmol} / \mathrm{l}$ HEPES (pH 7.4), $1 \mathrm{mmol} / \mathrm{l}$ sodium pyruvate and $50 \mu \mathrm{mol} / \mathrm{l} \beta$-mercaptoethanol.

Perifusions and static incubations Islet perifusions were performed as described [24] with the following modifications: after a 20-min equilibration period with KRB solution containing $0.1 \%$ (wt/vol.) BSA and $2.8 \mathrm{mmol} / 1$ glucose, islets were perifused for $40 \mathrm{~min}$ with $16.7 \mathrm{mmol} / \mathrm{l}$ glucose with or without $0.5 \mathrm{mmol} / \mathrm{l}$ oleate. Oleate was pre-complexed for $1 \mathrm{~h}$ at $37^{\circ} \mathrm{C}$ with fatty-acid-free BSA to a final molar ratio of $1: 5$ as described [25]. Control conditions contained the same amount of BSA and vehicle (50\% [vol./vol.] ethanol). For static incubations, batches of ten islets each were starved twice in KRB solution containing $0.1 \%$ (wt $/ \mathrm{vol}$.) BSA and $2.8 \mathrm{mmol} / 1$ glucose for $20 \mathrm{~min}$ at $37^{\circ} \mathrm{C}$, then incubated for $1 \mathrm{~h}$ in the presence of various secretagogues as described in Results. Each condition was run in triplicate. Intracellular insulin content was measured after acid-alcohol extraction. Insulin was measured by radioimmunoassay using rat insulin RIA kit (Millipore, Billerica, MA, USA).

Adenovirus infection Mouse islets were infected with adenoviruses after partial dissociation to ensure penetration of the viruses into the islet core. After isolation, the islets were washed twice with $1 \mathrm{ml}$ dissociation buffer $(1 \times$ Hank's balanced salt solution (HBSS), $20 \mathrm{mmol} / 1 \mathrm{HEPES}, 5 \mathrm{mmol} / \mathrm{l} \mathrm{glu}-$ cose and $1 \mathrm{mmol} / 1 \mathrm{EGTA}$ ), and incubated for $3 \mathrm{~min}$ at $37^{\circ} \mathrm{C}$ with $0.5 \mathrm{ml}$ dissociating buffer. Islets were then infected with $2 \times 10^{7}$ plaque-forming units (pfu)/(100 islets) of adenoviruses for $24 \mathrm{~h}$, after which the medium was replaced with complete medium and cultured for an additional 4 days in a humidified atmosphere with $5 \% \mathrm{CO}_{2}$ at $37^{\circ} \mathrm{C}$.

Cortical actin staining Mouse islets were dispersed into single cells by incubation for $11 \mathrm{~min}$ at $37^{\circ} \mathrm{C}$ in calciumfree buffer followed by gentle trituration with a flamepolished glass pipette, and then the cells were attached overnight to a coverslip. The cells were starved for $1 \mathrm{~h}$ in KRB ( $1 \mathrm{mmol} / \mathrm{l}$ glucose and $0.1 \%(\mathrm{wt} / \mathrm{vol}$.) BSA), followed by incubation at indicated conditions. Next, cells were fixed with Z-FIX (Anatech, Battle Creek, MI, USA) and stained for insulin (rabbit anti-insulin primary antibody; Santa Cruz
Biotechnology, Santa Cruz, CA, USA; and Alexa Fluor 594or Alexa Fluor 350-conjugated goat anti-rabbit secondary antibody; Invitrogen) and for filamentous actin (F-actin) (Alexa Fluor 488- or Alexa Fluor 565-conjugated phalloidin; Invitrogen). Cells were imaged with a Zeiss Axio Observer.Z1 microscope and $\times 63$ Plan ApoChromat objective (1.4 NA). Excitation was with a COLIBRITM (Carl Zeiss Canada, Toronto, ON, Canada) LED light source with 350,495 or $555 \mathrm{~nm}$ filter set. Insulin-positive cells were used for F-actin intensity measurement.

Cellular fractionation INS832/13 cells were washed with cold PBS $1 \mathrm{X}$ and homogenised at $4^{\circ} \mathrm{C}$ in buffer A $(20 \mathrm{mmol} / \mathrm{l}$ Tris$\mathrm{HCl}, \mathrm{pH} 7.5 / 2 \mathrm{mmol} / \mathrm{l}$ EDTA. $0.5 \mathrm{mmol} / \mathrm{l}$ EGTA, $1 \mathrm{mmol} / 1$ phenylmethylsulfonyl fluoride, $25 \mu \mathrm{g} / \mathrm{ml}$ leupeptin, $0.1 \mathrm{mg} / \mathrm{ml}$ aprotinin and $0.33 \mathrm{~mol} / \mathrm{l}$ sucrose) and centrifuged at $1,000 \mathrm{~g}$ for $10 \mathrm{~min}$. The supernatant fraction was ultracentrifuged at $100,000 \mathrm{~g}$ for $30 \mathrm{~min}$ at $4^{\circ} \mathrm{C}$ and the resultant supernatant fraction was retained as the cytosolic fraction. The pellets were washed and resuspended in buffer B (buffer A without sucrose) and homogenised again. The homogenates were solubilised in buffer B with $1 \%$ (wt/vol.) Triton X-100. After incubating for $45 \mathrm{~min}$, soluble fractions were obtained by ultracentrifugation at $100,000 \mathrm{~g}$ for $30 \mathrm{~min}$ and were retained as membrane fractions.

Western blots Protein extracts were separated on 7.5\% (wt/vol.) SDS-PAGE, blotted to nitrocellulose membranes, incubated overnight at $4{ }^{\circ} \mathrm{C}$ with primary antibodies and visualised with horseradish peroxidase-labelled anti-rabbit or anti-mouse IgG as secondary antibodies. Bands were quantified by ImageJ software (http://rsbweb.nih.gov/ij/).

Quantitative RT-PCR The method for quantitative RT-PCR and list of primers are described in electronic supplementary materials (ESM) Methods.

Statistics Data are expressed as mean \pm SEM and were analysed by one or two-way ANOVA with Bonferroni post-hoc adjustment for multiple comparisons, or Student's paired $t$ test, where appropriate. $p<0.05$ was considered significant.

\section{Results}

Oleate potentiates the second phase of GSIS in isolated mouse islets in large part via GPR40 Fatty acids are known to potentiate GSIS via both GPR40-dependent and -independent pathways. To determine the kinetics of the potentiation of GSIS by fatty acids and the contribution of GPR40 to phasic insulin release, insulin secretion was measured in perifusion experiments from islets isolated from $\mathrm{Gpr}_{4} \mathrm{O}^{-/-}$mice and WT littermates in response 
to $16.7 \mathrm{mmol} / 1$ glucose in the presence or absence of $0.5 \mathrm{mmol} / 1$ oleate (Fig. 1a, b). We observed that GSIS was similar between WT and $\mathrm{Gpr} 40^{-/-}$islets. The addition of oleate greatly potentiated the glucose response in islets from WT mice (AUC: $1.6 \pm 0.3$ vs $0.3 \pm 0.1$ arbitrary units, $n=4, p<0.001$ ), and essentially restored a large second phase of insulin secretion. Oleate potentiation of GSIS was strongly reduced in islets from $\mathrm{Gpr} 4 \mathrm{O}^{-/-}$mice (AUC: $0.7 \pm 0.1$ vs $1.6 \pm 0.3$ arbitrary units, $n=4, p<0.001$ ). These results indicate that oleate potentiates predominantly the second phase of GSIS and that GPR40 mediates more than half of this effect.

Oleate promotes cortical actin depolymerisation via GPR40 Potentiation of insulin secretion is associated, if not directly enabled, by reorganisation of the cytoskeleton to promote access of secretory granules to the plasma membrane [26]. Based on the predominant stimulation of secondphase GSIS by fatty acids (Fig. 1a, b), we examined the effects of oleate on cortical actin depolymerisation. After incubation in $16.7 \mathrm{mmol} / 1$ glucose with or without $0.5 \mathrm{mmol} / 1$ oleate, single beta cells from WT and $\mathrm{Gpr}_{40} \mathrm{O}^{-/-}$ mice were fixed and stained for insulin and F-actin and visualised by epifluorescence microscopy (Fig. 2a, b). Under non-stimulatory conditions, F-actin staining appeared as a ring in close proximity to the plasma membrane (Fig. 2a). As expected, glucose time-dependently induced F-actin depolymerisation (shown in Fig. 2a by the disappearance of the ring-shaped F-actin staining) in both WT and $\mathrm{Fpr}_{4} \mathrm{O}^{-/-}$ beta cells. Oleate rapidly reduced F-actin intensity in WT beta cells, but was ineffective in $\mathrm{Gpr} 40^{-/-}$beta cells after 5 min of incubation, whereas the depolymerising agent latrunculin was equally effective in beta cells from both genotypes. After 15 min of incubation with oleate, F-actin intensity was decreased by about $15 \%$, consistent with the

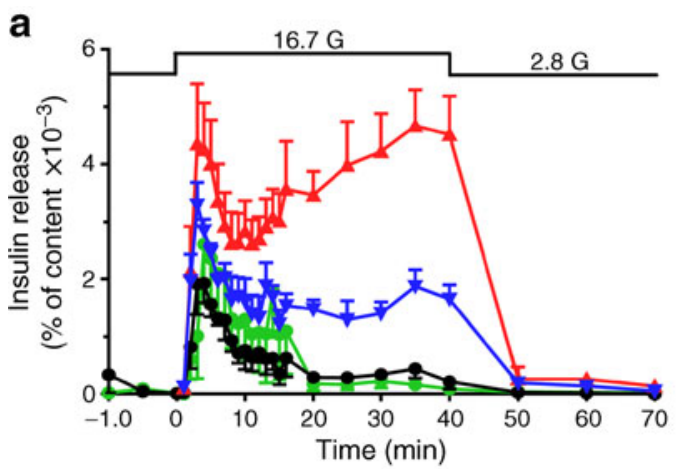

Fig. 1 Oleate potentiates the second phase of GSIS largely via GPR40. (a) Insulin secretion in response to $2.8 \mathrm{mmol} / 1$ glucose from -10 to $0 \mathrm{~min}$ (all groups), $16.7 \mathrm{mmol} / \mathrm{l}$ glucose (black and green lines) or $16.7 \mathrm{mmol} / \mathrm{l}$ glucose $+0.5 \mathrm{mmol} / \mathrm{l}$ oleate (blue and red lines) from 0 to $40 \mathrm{~min}$, and $2.8 \mathrm{mmol} / \mathrm{l}$ glucose from 40 to $70 \mathrm{~min}$ (all groups) in WT (black and red) or $\mathrm{Fpr}_{4} \mathrm{O}^{-/-}$islets (green and blue lines) in perifusion experiments. (b) observation that oleate retained some ability to potentiate GSIS in the absence of GPR40 (Fig. 1a), an effect likely due to intracellular metabolism of fatty acids [27]. Thus, oleate promotes rapid F-actin depolymerisation in a GPR40dependent manner.

$D A G$ mimics the effect of oleate on GSIS independently from GPR40 To test the involvement of the DAG branch of GPR40 signalling on insulin secretion, we exposed isolated islets from WT and $\mathrm{Fpr}_{4} \mathrm{O}^{-1-}$ mice to glucose in the absence or presence of oleate and/or the cell-permeable 1,2dioctanoyl-DAG $(100 \mu \mathrm{mol} / \mathrm{l}$; Fig. 3a, b). In WT islets, exogenous DAG had no effect on insulin secretion at basal glucose concentration but potentiated GSIS to a similar level as oleate. The stimulation of GSIS by DAG was not additive to that of oleate (Fig. 3a). In contrast, the cAMP-raising agent IBMX $(100 \mu \mathrm{mol} / \mathrm{l})$ further potentiated insulin secretion induced by glucose and oleate (Fig. 3c), excluding the possibility that the maximal secretory capacity had been reached with oleate. In $\mathrm{Gpr} 4 \mathrm{O}^{-/-}$islets oleate did not potentiate GSIS but the effect of DAG was preserved (Fig. 3b). These results are consistent with the possibility that DAG acts as a signalling molecule downstream of GPR40.

Oleate phosphorylates PKD via GPR40 PKD is a DAGsensitive kinase involved in the regulation of insulin secretion in response to the M3-muscarinic receptor [28, 29]. There are three isoforms of PKD (PKD1-3) encoded by three different genes. Of these, we found PKD1 to be the most abundantly produced at the mRNA level in isolated mouse islets (ESM Fig. 1a). Also, PKD1 protein was readily detected in islets but undetectable in pancreatic exocrine cells (ESM Fig. 1b). In response to $\mathrm{G}_{\alpha \mathrm{\alpha} / 11}$ stimulation, DAG binding to the $\mathrm{C} 1$ domain of PKD1 promotes its translocation to the plasma membrane [30] and its activation

\section{b}

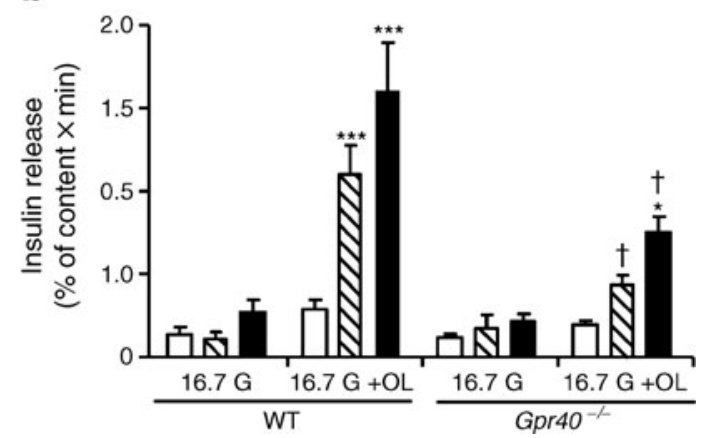

Calculation of the AUC from 0 to $10 \mathrm{~min}$ (white bars), from 10 to $40 \mathrm{~min}$ (hatched bars), and from 0 to $40 \mathrm{~min}$ (black bars). Results are mean $\pm \mathrm{SEM}$ of four independent experiments. G, glucose; OL, oleate. ${ }^{*} p<0.05$, ${ }^{* *} p<0.01$ and $* * * p<0.001$ compared with the $16.7 \mathrm{mmol} / 1(16.7 \mathrm{G})$ condition for each genotype; ${ }^{\dagger} p<0.001$ compared with the respective condition in WT 
a $16.7 \mathrm{G}$

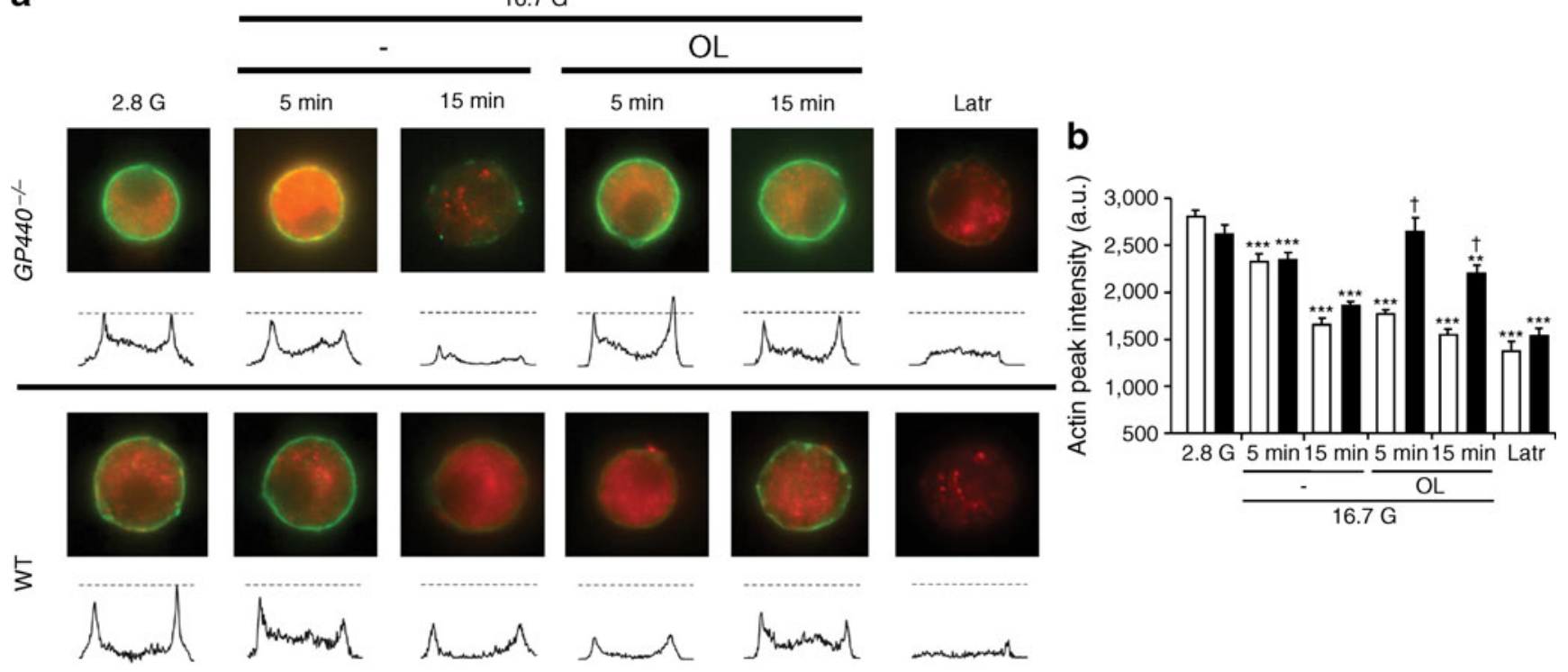

Fig. 2 Oleate induces cortical F-actin depolymerisation. (a) Representative images for $\mathrm{F}$-actin staining (green) for each incubation condition with intensity line scans for F-actin staining intensity. Dashed lines represent the F-actin intensity means for the $2.8 \mathrm{mmol} / \mathrm{l}$ glucose $(2.8 \mathrm{G})$ condition. Beta cells were identified by insulin staining (red). (b) Mean \pm SEM of F-actin intensities from 40-62 cells from three WT (white bars) or $\mathrm{Fpr}_{40} \mathrm{O}^{-/-}$(black bars) mice. a.u., arbitrary units; G, glucose; Latr, latrunculin; OL, oleate. ${ }^{*} p<0.05, * * p<0.01$ and $* * * p<0.001$ compared with the $2.8 \mathrm{G}$ condition for each genotype, ${ }^{\dagger} p<0.001$ compared with the respective condition in WT by sequential phosphorylation at Ser-744 and Ser-748 in the activation loop and autophosphorylation at Ser-916, which promotes the full catalytic activity of the kinase [31]. We observed that incubation of INS832/13 cells with oleate induced rapid PKD phosphorylation at both Ser-744/748 and Ser-916 with no changes in total PKD1 levels in whole-cell extracts (Fig. 4a). The effect was detected at $5 \mathrm{~min}$, reached a maximum at $20 \mathrm{~min}$, remained stable for $1 \mathrm{~h}$ for Ser-744/748, and decreased thereafter for Ser-916 (Fig. 4b, c). Exogenous DAG induced PKD phosphorylation to similar degree as oleate. Cellular fractionation showed that phospho-Ser-744/748 was undetectable in the cytoplasmic fraction but increased in the membrane fraction in response to oleate or DAG (Fig. 4d, f). Interestingly, total PKD1 levels also increased at the membrane in response to oleate or DAG, suggesting translocation of the enzyme.

Phosphorylation of PKD at both Ser-744/748 and Ser-916 in response to oleate was completely abolished in $\mathrm{Gpr}_{4} \mathrm{O}^{-1-}$ islets (Fig. 4g). In contrast, exogenous DAG was equally effective in WT and $\mathrm{Fpr}_{40} \mathrm{O}^{-1-}$ islets. Altogether, these data show that oleate activates PKD in a GPR40-dependent manner, and suggest that this effect might be mediated by intracellular DAG.

PKD1 mediates fatty-acid potentiation of GSIS via GPR40 We used pharmacological and molecular approaches to assess the functional role of PKD1 in the potentiation of GSIS by oleate in 1-h static incubations in islets. First, the PKD
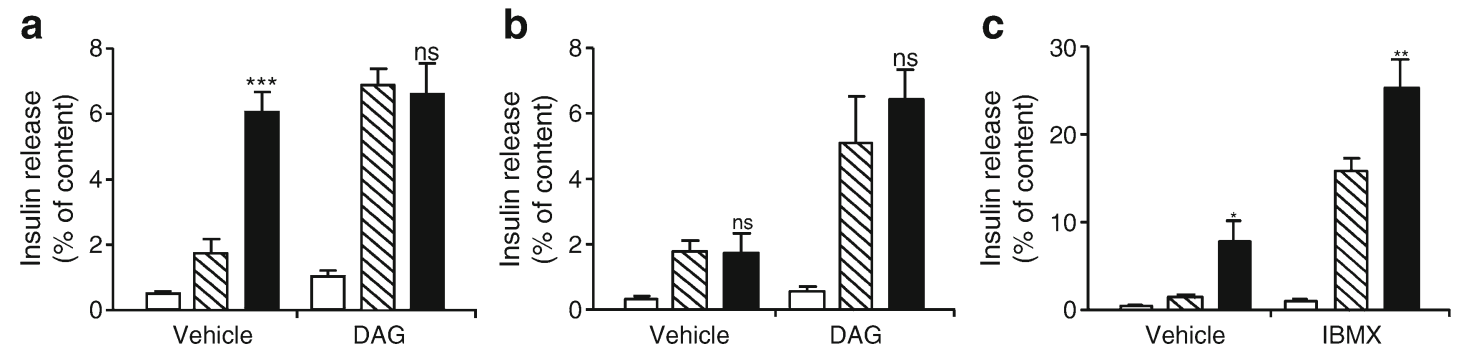

Fig. 3 Exogenous DAG potentiates GSIS in islets from WT and $\mathrm{Gpr}_{40} 0^{-1-}$ mice. (a, b) Insulin secretion from WT (a) and $\mathrm{Gpr}_{40} 0^{-1-}$ (b) islets was assessed in $1 \mathrm{~h}$ static incubations in the presence of $2.8 \mathrm{mmol} / \mathrm{l}$ glucose (white bars), $16.7 \mathrm{mmol} / \mathrm{l}$ glucose (hatched bars) or $16.7 \mathrm{mmol} / \mathrm{l}$ glucose $+0.5 \mathrm{mmol} / \mathrm{l}$ oleate (black bars) $\pm 0.1 \mathrm{mmol} / 1$ 1,2-dioctanoyl-DAG. (c) Insulin secretion from WT islets was assessed in the presence of
$2.8 \mathrm{mmol} / \mathrm{l}$ glucose (white bars), $16.7 \mathrm{mmol} / \mathrm{l}$ glucose (hatched bars) or $16.7 \mathrm{mmol} / 1$ glucose $+0.5 \mathrm{mmol} / 1$ oleate (black bars) $\pm 0.1 \mathrm{mmol} / 1 \mathrm{IBMX}$. Data are mean \pm SEM of three independent experiments. ns, not significant; ${ }^{*} p<0.05,{ }^{* *} p<0.01$ and ${ }^{* * *} p<0.001$ compared with the $16.7 \mathrm{mmol} / \mathrm{l}$ glucose $(16.7 \mathrm{G})$ condition for each genotype 

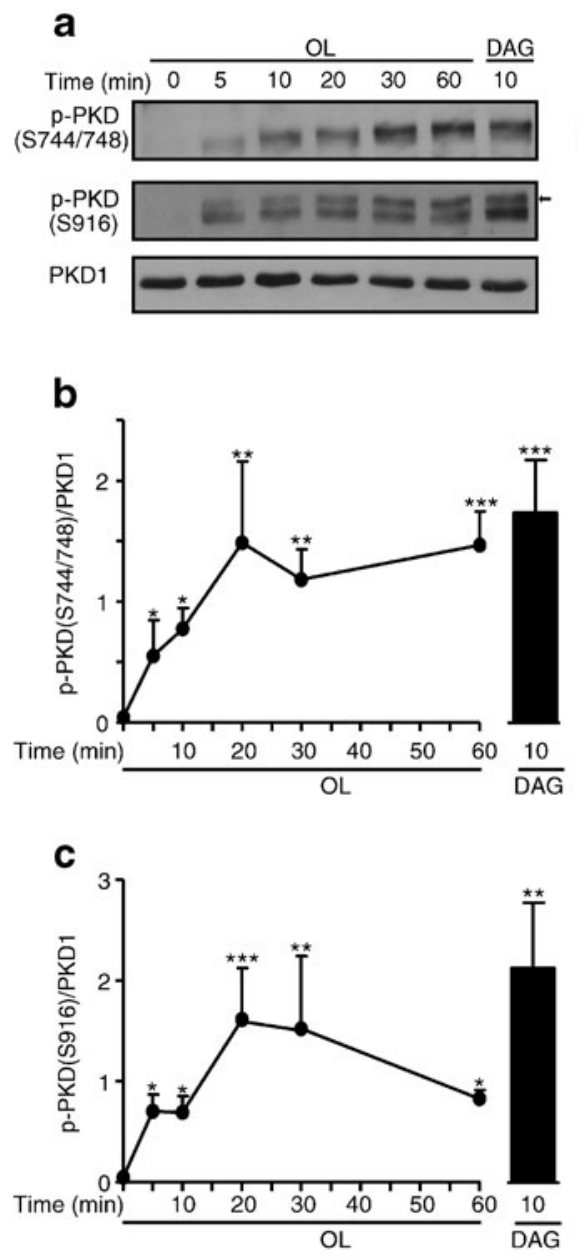
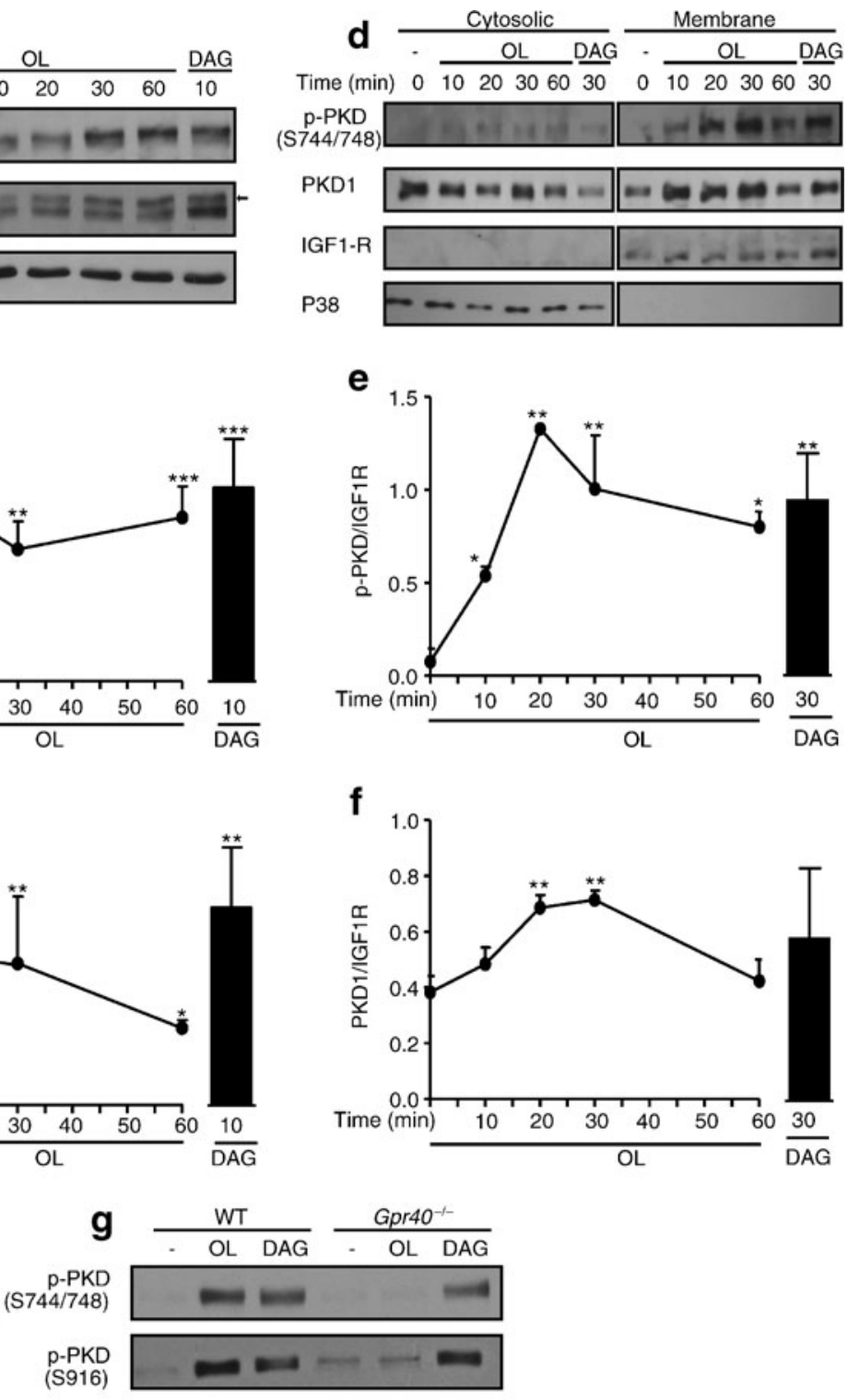

PKD1

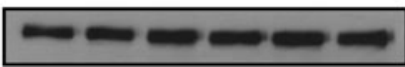

Fig. 4 Oleate phosphorylates PKD1 in a GPR40-dependent manner. (a) Representative immunoblots of phospho-Ser-744/748 (S744/748) PKD, phospho-Ser-916 (S916) PKD and total PKD1 in protein extracts of INS832/13 cells exposed at indicated time to $16.7 \mathrm{mmol} / 1$ glucose $\pm 0.5 \mathrm{mmol} / 1$ oleate or $0.1 \mathrm{mmol} / 1$ 1,2-dioctanoyl-DAG. The arrow shows S916 PKD based on the expected molecular mass. (b, c) Quantitative measurements of phospho-Ser-744/748 PKD (b) and phosho-Ser916 PKD (c) in INS832/13 cells. (d) Representative immunoblots of phospho-S744/748 PKD and total PKD1 in cytosolic and membrane fractions of INS832/13 cells exposed to $16.7 \mathrm{mmol} / 1$ glucose $\pm 0.5 \mathrm{mmol} / 1$ oleate $(\mathrm{OL})$ or $0.1 \mathrm{mmol} / 1$ 1,2-dioctanoyl-DAG. Immunoblots of P38 and IGF1R were used as cytosolic and membrane markers, respectively. (e, f) Quantitative measurements of phospho-S744/748 PKD (e) and total PKD1 (f) in cytosolic fractions. (g) Representative immunoblots of S744/748 PKD, S916 PKD and total PKD1 in WT and Gpr40 islets exposed for $30 \mathrm{~min}$ to $16.7 \mathrm{mmol} / 1$ glucose $\pm 0.5 \mathrm{mmol} / 1$ oleate or $0.1 \mathrm{mmol} / 1$ 1,2-dioctanoyl-DAG. Data are mean $\pm \mathrm{SEM}$ of three independent experiments. ${ }^{*} p<0.05,{ }^{* *} p<0.01$, and ${ }^{* * *} p<0.001 \mathrm{com}-$ pared with time 0 inhibitor rottlerin ( $10 \mu \mathrm{mol} / 1$, Fig. 5a, inset) completely blocked the potentiating effect of oleate $(p<0.001)$ in WT islets (Fig. 5a). Second, isolated islets from Prkdl flox/flox mice were infected with Ad-Cre or Ad-GFP as a control. Ad-Cre-infected islets had a $\sim 75 \%$ reduction in PKD1 protein levels (Fig. 5b, inset) and a marked reduction in the potentiation of GSIS by oleate, without significant changes in GSIS (Fig. 5b).

$\mathrm{PKC} \delta$ is a DAG-activated isoform of PKC that is also inhibited by rottlerin and has been suggested to phosphorylate PKD at Ser-744/748 [32]. Therefore, we assessed the potential 
involvement of PKC $\delta$ in GPR40 signalling by measuring insulin secretion in islets from Prkcd $^{/-}$mice (Fig. 5c). We observed that both GSIS and its potentiation by oleate were completely preserved in $\mathrm{Prkcd}^{-1}$ islets (Fig. 5c). Altogether, these results indicate that PKD1, but not PKC $\delta$, is required for the potentiation of GSIS by oleate.

Cortical actin depolymerisation in response to oleate requires PKD1 To assess the involvement of PKD1 in GPR40mediated F-actin depolymerisation, single beta cells from PrkdI $I^{\text {flox/flox }}$ islets infected with Ad-Cre or Ad-GFP were incubated with $16.7 \mathrm{mmol} / \mathrm{l}$ glucose in the presence or absence of oleate for $5 \mathrm{~min}$ (Fig. 6a, b). Oleate induced F-actin depolymerisation in Ad-GFP-infected beta cells, but this effect was completely abrogated in Ad-Cre-infected beta cells. The effects of glucose and the depolymerising agent latrunculin were unaltered by PKD1 deletion. These results demonstrate that PKD1 is necessary for oleate to promote F-actin depolymerisation.

\section{Discussion}

The aim of this study was to identify the signalling pathway activated downstream of the fatty-acid receptor GPR40 in pancreatic beta cells. We found that oleate potentiates preferentially the second phase of GSIS, largely through GPR40. This effect is associated with rapid and GPR40-dependent Factin depolymerisation and activation of PKD. Further, pharmacological inhibition or deletion of the gene encoding PKD1, but not PKC $\delta$, blocks fatty-acid potentiation of GSIS. Finally, deletion of the gene encoding PKD1 blocks the ability of oleate to induce F-actin depolymerisation. These results uniquely demonstrate that PKD1 is activated downstream of
GPR40 and is required for the potentiation of insulin secretion by fatty acids.

Since its deorphanisation as a GPCR activated by medium- to long-chain fatty acids [4-6], GPR40 received considerable attention as potential target for type 2 diabetes therapy. The druggability of GPCRs in general, the relative selectivity of GPR 40 production in beta cells, and the 'incretin-like' effects of long-chain fatty acids, which only stimulate insulin secretion when glucose levels are elevated, all favour the development of GPR40 agonists to enhance insulin secretion in type 2 diabetes without the risk of hypoglycaemia $[4,5]$. However, because prolonged exposure to elevated levels of fatty acids is detrimental to beta cell function [33], the possibility that chronic stimulation of GPR40 might be deleterious led some groups to propose that GPR40 antagonists - rather than agonists - should be designed for therapeutic purposes [34, 35]. Thus, Steneberg et al [35] reported that $\mathrm{Gpr}_{40} \mathrm{O}^{-/}$mice are protected from high-fat-diet-induced insulin resistance and glucose intolerance and that transgenic overexpression of GPR40 in beta cells impairs insulin secretion. However, subsequent studies in $\mathrm{Gpr}^{-1-}[14,16]$ and transgenic mice [10] or using GPR40 agonists [11-13] all concur to support the agonist approach. In fact, several GPR40 agonists are under clinical development, and one of them showed very promising results in a phase 2 clinical trial $[18,19]$.

Despite the intense interest in the pharmacology of GPR40 as a therapeutic target, comparatively little is known about the biology of the receptor. In this study we first examined the kinetics of fatty-acid effects on GSIS in perifusion experiments. As expected, in mouse islets [36] the response to glucose was biphasic: a rapid first phase was followed by a relatively flat second phase. Also in line with previous reports $[4,7]$, GSIS was similar between WT and $\mathrm{Fpr}_{4} \mathrm{O}^{-/-}$islets. Interestingly, oleate potentiated preferentially the second
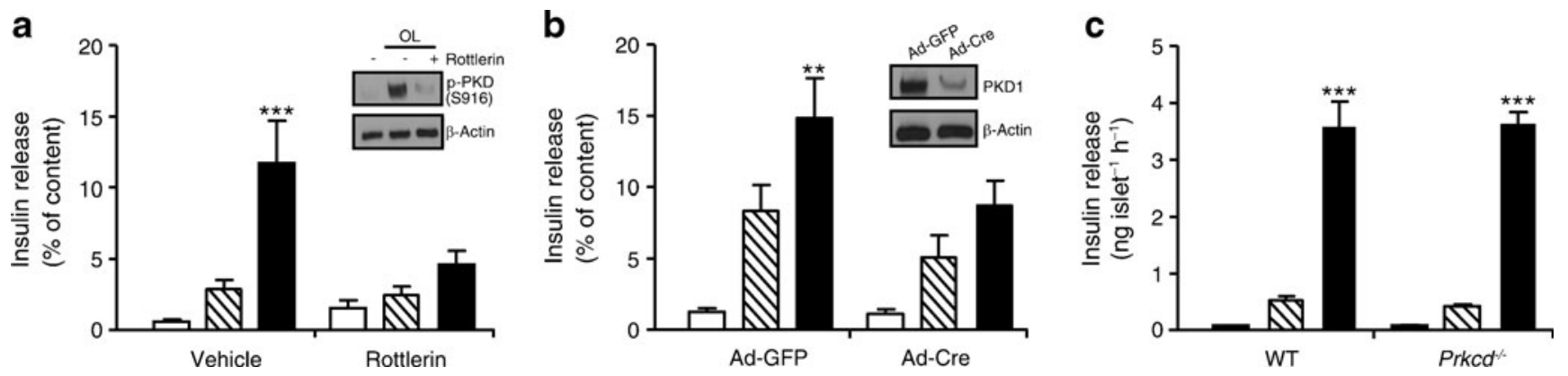

Fig. 5 PKD1 mediates the potentiation of GSIS by oleate. (a) WT islets were preincubated with $10 \mu \mathrm{mol} / 1$ rottlerin for $40 \mathrm{~min}$, and insulin secretion was assessed in a 1-h static incubation in the presence of $2.8 \mathrm{mmol} / 1$ glucose (white bars), $16.7 \mathrm{mmol} / 1$ glucose (hatched bars) or $16.7 \mathrm{mmol} / \mathrm{l}$ glucose $+0.5 \mathrm{mmol} / \mathrm{l}$ oleate (OL; black bars) $\pm 10 \mu \mathrm{mol} /$ 1 rottlerin. Inset: representative immunoblot of $\mathrm{S} 916 \mathrm{PKD} \pm$ rottlerin. (b) Insulin secretion from Ad-GFP- or Ad-Cre-infected Prkd1 $1^{\text {flox/flox }}$ islets was assessed in 1-h static incubations in the presence of $2.8 \mathrm{mmol} / \mathrm{l}$ glucose (white bars), $16.7 \mathrm{mmol} / \mathrm{l}$ glucose (hatched bars) or $16.7 \mathrm{mmol} / 1$ glucose $+0.5 \mathrm{mmol} / 1$ oleate (black bars). Inset: representative immunoblots of deletion efficiency. (c) Insulin secretion from WT and $\mathrm{Prkd}^{-1}$ islets was assessed in 1-h static incubations in the presence of $2.8 \mathrm{mmol} / 1$ glucose (white bars), $16.7 \mathrm{mmol} / 1$ glucose (hatched bars) or $16.7 \mathrm{mmol} / 1$ glucose + $0.5 \mathrm{mmol} / 1$ oleate (black bars). Data are mean \pm SEM of three or four independent experiments. $* * p<0.01, * * * p<0.001$ compared with the $16.7 \mathrm{mmol} / 1$ glucose $(16.7 \mathrm{G})$ condition for each genotype 

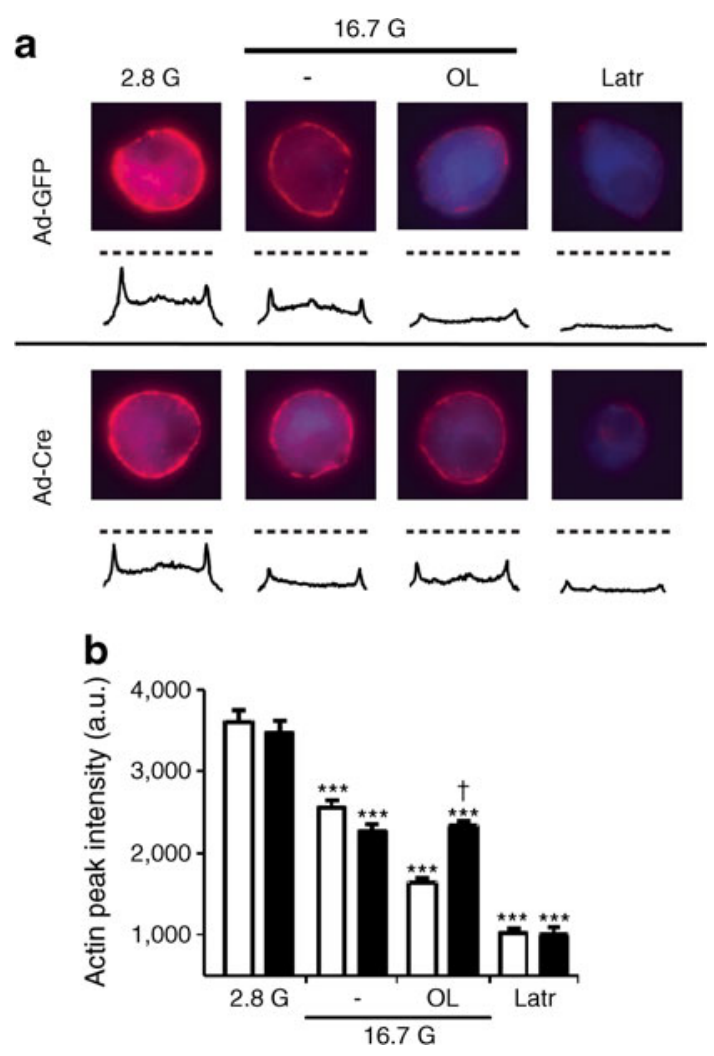

Fig. 6 PKD1 is necessary for oleate-mediated F-actin depolymerisation. (a) Representative images for F-actin staining (red) for each incubation condition with intensity line scans for F-actin staining intensity. Dashed lines represent the F-actin intensity means for the $2.8 \mathrm{G}$ condition. Beta cells were identified by insulin staining (blue). (b) Mean \pm SEM F-actin intensities from 20-35 cells, from three mice, of Ad-GFP (white bars)- or Ad-Cre (black bars)-infected Prkd1 $1^{\text {flox/llox }}$ islets. a.u., arbitrary units; Latr, latrunculin. ${ }^{* * *} p<0.001$ compared with the $2.8 \mathrm{mmol} / 1$ glucose $(2.8 \mathrm{G})$ condition for each condition; ${ }^{\dagger} p<0.001$ compared with the respective condition in Ad-GFP

phase of insulin secretion in WT islets, and at least half of this effect was eliminated in $\mathrm{Gpr}_{4} \mathrm{O}^{-/-}$islets. This is consistent with our previous observations that the second phase of insulin secretion is reduced by approximately $50 \%$ in $\mathrm{Gpr}_{40} \mathrm{O}^{--}$ mice both in response to Intralipid [7] and during intravenous glucose tolerance tests following high-fat feeding [14]. Overall, these findings suggest that approximately half of the stimulating effect of fatty acids on insulin secretion is mediated by GPR 40, the other half being likely related to their intracellular metabolism $[8,27]$. A model to explain the biphasic nature of insulin release induced by nutrients proposes that first-phase secretion is mediated by the release of a readily releasable pool of insulin secretory granules pre-docked at the plasma membrane, whereas the second phase of insulin release involves the transport of insulin granules from an intracellular reserve pool to the plasma membrane [26]. Consistent with this model, intracellular granule transport is associated with remodelling of the actin cytoskeleton, and blockade of
F-actin depolymerisation specifically reduces second-phase insulin secretion $[37,38]$. Here we observed that fatty acids largely amplified the second phase of GSIS and that this was associated with a rapid and GPR40-dependent depolymerisation of F-actin. This suggests that GPR40 signalling regulates the actin cytoskeleton and, thereby, second-phase insulin secretion. In apparent contradiction with our results, a GPR40 agonist has been reported to potentiate both first- and secondphase insulin release [39]. This discrepancy might be due either to differences between fatty acids and the agonist, or to the fact that in that study the islets were pre-treated with the agonist before the insulin secretion test, which might have 'primed' the pathway.

GPR40 is thought to couple to $G_{\alpha q / 11}$, which classically activates PLC $[5,7,20]$. Although the rise in IP3 levels in response to fatty acids does not occur in $\mathrm{Fpr}_{40} \mathrm{O}^{-1-}$ islets [8], the functional role of IP3 in the potentiation of insulin secretion by fatty acids remains unclear. In fact, the increase in the level of intracellular calcium in response to fatty acids appears to be due to modulation of ATP-sensitive potassium channel and L-type calcium channel activity rather than to the mobilisation of $\mathrm{Ca}^{2+}$ from ER stores [21, 40]. Thus, inhibition of the ER calcium ATPase pump, which leads to depletion of $\mathrm{ER}^{2}{ }^{2+}$ stores, does not prevent the rise in intracellular $\mathrm{Ca}^{2+}$ in response to oleic acid [21]. In addition, inhibition of IP3-mediated $\mathrm{Ca}^{2+}$ release from the ER has no effect on the potentiation of insulin secretion by a GPR 40 agonist [41]. Here we showed that exogenous DAG mimicked the potentiating effect of oleate on insulin secretion in both WT and $G p r 40^{-/-}$islets. This is consistent with the possibility that DAG generation in response to GPR40 activation mediates most of the GPR40-dependent effects of fatty acids on insulin secretion, with only a minor contribution (if any) of the IP3 branch of the pathway (Fig. 7).

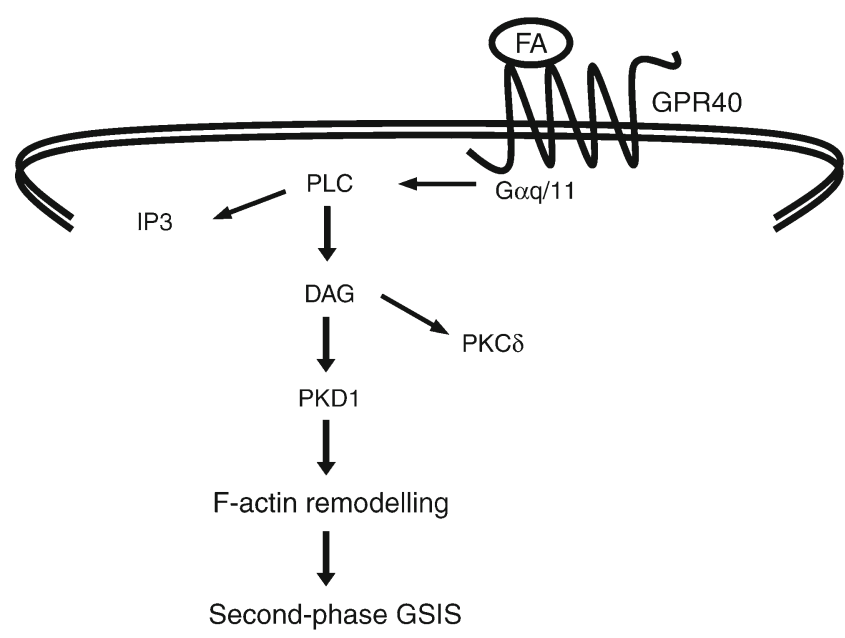

Fig. 7 A model for GPR40-dependent potentiation of GSIS by fatty acids (FA) 
PKD is a serine/threonine kinase initially described as an atypical PKC (PKC $\mu)$ but now classified as a subfamily of the $\mathrm{Ca}^{2+} /$ calmodulin-dependent kinase superfamily [42]. The role of PKD in beta cell function was first demonstrated by Sumara et al [29], who showed that PKD1 was negatively regulated by the $\delta$ isoform of p38 mitogen-activated protein kinase and promoted both insulin secretion and beta cell survival. Kong et al [28] further showed that PKD1 mediates insulin secretion in response to muscarinic stimulation. Here, we provide unique evidence that PKD is also activated rapidly, in a GPR40-dependent manner, in response to oleate. Further, pharmacological inhibition or deletion of the gene encoding PKD1 abrogates the potentiation of GSIS by oleate without significantly affecting GSIS itself. These results therefore demonstrate a key role for PKD1 in GPR40 signalling in response to fatty acids.

One question that arises from these findings is: how is PKD1 activated in response to fatty acids? Our observation that exogenous DAG promotes PKD phosphorylation at both Ser-744/748 and Ser-916 suggests the involvement of a $\mathrm{G}_{\alpha \mathrm{\alpha} / 11}$-dependent signalling pathway, PLC activation and DAG generation. In aortic smooth muscle cells, PKD is first activated by PKC $\delta$-mediated trans-phosphorylation at Ser$744 / 748$ [32]. In beta cells, however, our [43, 44] and other [45] previous observations that glucose and phorbol esterstimulated insulin secretion are unaltered by deletion or overexpression of a kinase-negative isoform of $\mathrm{PKC} \delta$, as well as the current results showing normal fatty-acid potentiation of GSIS in Prkcd ${ }^{--}$islets, suggest that PKC $\delta$ is unlikely involved, in this context, in trans-phosphorylation of PKD. Alternatively, it is possible that GPR40 signalling activates PKD via $\mathrm{G}_{\alpha \mathrm{q}}$-dependent autophosphorylation [31, 46] or, as shown for M3-muscarinic receptor stimulation of insulin release, by G-protein-independent, $\beta$-arrestindependent activation [28]. However, since exogenous DAG mimics the effect of oleate on PKD activation and insulin secretion, and since inhibition of $G_{\alpha q / 11}$ inhibits fatty-acid potentiation of GSIS [7], it is likely that GPR40 signalling involves a $G_{\alpha q / 11}$-dependent pathway rather than a G-protein independent mechanism.

A second question arising from our results is: how does PKD1 promote second-phase insulin secretion in response to fatty acids? In this regard, our finding that deletion of the gene encoding PKD1 in islets prevents oleate-induced F-actin depolymerisation is consistent with the observation that PKD phosphorylates several proteins that regulate F-actin remodelling in other cell types and control insulin secretion in beta cells, such as the small GTPase RhoA $[47,48]$ or p21activated kinase [37, 49], although the nature of PKD1 targets in this particular context remains to be identified.

In conclusion, our findings are consistent with the model depicted in Fig. 7 by which fatty-acid stimulation of GPR40, coupled to $G_{\alpha q / 11}$, results in the generation of DAG via
PLC-mediated hydrolysis of membrane phospholipids, activation of PKD1, F-actin depolymerisation, and potentiation of second-phase GSIS. These observations provide valuable mechanistic information as GPR40 is being considered as a target for type 2 diabetes therapy and several GPR40 agonists are in the advanced phase of clinical development.

Acknowledgements This work was supported by the Canadian Institutes of Health Research (CIHR; MOP 86545 to V. Poitout) and the Canadian Diabetes Association (to P. E. MacDonald). M. Ferdaoussi is supported by fellowships from Diabète Québec and the CRCHUM. V. Poitout holds the Canada Research Chair (CRC) in Diabetes and Pancreatic Beta-cell Function. M. Prentki holds the CRC in Diabetes and Metabolism. P. E. MacDonald holds the CRC in Islet Biology and a scholarship from Alberta Innovates - Health Solutions (AI-HS). J. Kolic is supported by doctoral studentships from AI-HS and the CIHR. We thank: M. Ethier (CRCHUM) and G. Fergusson (CRCHUM) for valuable technical assistance; A. Smith (University of Alberta) for assistance with image analysis; D. C. Lin and H. Baribault (Amgen) for providing $\mathrm{Gpr}_{4} \mathrm{O}^{-1-}$ breeders and M. Leitges (Biotechnology Centre of Oslo, Oslo, Norway) for providing $P k c \delta^{-1}$ mice.

Duality of interest V. Poitout has served as a consultant to Takeda and Merck Research Laboratories in the past 12 months. All other authors declare that there is no duality of interest associated with this manuscript.

Contribution statement MF and VP designed research and wrote the paper. All authors contributed to acquisition, analysis and interpretation of data, revised the manuscript and approved the final version.

\section{References}

1. Whiting DR, Guariguata L, Weil C, Shaw J (2011) IDF diabetes atlas: global estimates of the prevalence of diabetes for 2011 and 2030. Diabetes Res Clin Pract 94:311-321

2. Prentki M, Nolan CJ (2006) Islet beta cell failure in type 2 diabetes. J Clin Invest 116:1802-1812

3. Newsholme P, Gaudel C, McClenaghan NH (2010) Nutrient regulation of insulin secretion and beta-cell functional integrity. Adv Exp Med Biol 654:91-114

4. Itoh Y, Kawamata Y, Harada M et al (2003) Free fatty acids regulate insulin secretion from pancreatic beta cells through GPR40. Nature 422:173-176

5. Briscoe CP, Tadayyon M, Andrews JL et al (2003) The orphan G protein-coupled receptor GPR40 is activated by medium and long chain fatty acids. J Biol Chem 278:11303-11311

6. Kotarsky K, Nilsson NE, Olde B, Owman C (2003) Progress in methodology. Improved reporter gene assays used to identify ligands acting on orphan seven-transmembrane receptors. Pharmacol Toxicol 93:249-258

7. Latour MG, Alquier T, Oseid E et al (2007) GPR40 is necessary but not sufficient for fatty acid stimulation of insulin secretion in vivo. Diabetes 56:1087-1094

8. Alquier T, Peyot ML, Latour MG et al (2009) Deletion of GPR40 impairs glucose-induced insulin secretion in vivo in mice without affecting intracellular fuel metabolism in islets. Diabetes 58:26072615

9. Schmidt J, Liebscher K, Merten N et al (2011) Conjugated linoleic acids mediate insulin release through islet $\mathrm{G}$ protein-coupled receptor FFA1/GPR40. J Biol Chem 286:11890-11894 
10. Nagasumi K, Esaki R, Iwachidow K et al (2009) Overexpression of GPR40 in pancreatic beta-cells augments glucose-stimulated insulin secretion and improves glucose tolerance in normal and diabetic mice. Diabetes 58:1067-1076

11. Doshi LS, Brahma MK, Sayyed SG et al (2009) Acute administration of GPR40 receptor agonist potentiates glucosestimulated insulin secretion in vivo in the rat. Metabolism $58: 333-343$

12. Lin DC, Zhang J, Zhuang R et al (2011) AMG 837: a novel GPR40/FFA1 agonist that enhances insulin secretion and lowers glucose levels in rodents. PLoS One 6:e27270

13. Tsujihata Y, Ito R, Suzuki M et al (2011) TAK-875, an orally available $G$ protein-coupled receptor 40 /free fatty acid receptor 1 agonist, enhances glucose-dependent insulin secretion and improves both postprandial and fasting hyperglycemia in type 2 diabetic rats. J Pharmacol Exp Ther 339:228-237

14. Kebede M, Alquier T, Latour MG, Semache M, Tremblay C, Poitout V (2008) The fatty acid receptor GPR40 plays a role in insulin secretion in vivo after high-fat feeding. Diabetes 57:24322437

15. Tan CP, Feng Y, Zhou YP et al (2008) Selective small-molecule agonists of $\mathrm{G}$ protein-coupled receptor 40 promote glucosedependent insulin secretion and reduce blood glucose in mice. Diabetes 57:2211-2219

16. Lan H, Hoos LM, Liu L et al (2008) Lack of FFAR1/GPR40 does not protect mice from high-fat diet-induced metabolic disease. Diabetes 57:2999-3006

17. Wu P, Yang L, Shen X (2010) The relationship between GPR40 and lipotoxicity of the pancreatic beta-cells as well as the effect of pioglitazone. Biochem Biophys Res Commun 403:36-39

18. Araki T, Hirayama M, Hiroi S, Kaku K (2012) GPR40-induced insulin secretion by the novel agonist TAK-875: first clinical findings in patients with type 2 diabetes. Diabetes Obes Metab 14:271278

19. Burant CF, Viswanathan P, Marcinak J et al (2012) TAK-875 versus placebo or glimepiride in type 2 diabetes mellitus: a phase 2, randomised, double-blind, placebo-controlled trial. Lancet 379:1403-1411

20. Schroder R, Janssen N, Schmidt J et al (2010) Deconvolution of complex $\mathrm{G}$ protein-coupled receptor signaling in live cells using dynamic mass redistribution measurements. Nat Biotechnol 28:943-949

21. Fujiwara K, Maekawa F, Yada T (2005) Oleic acid interacts with GPR40 to induce $\mathrm{Ca} 2+$ signaling in rat islet beta-cells: mediation by PLC and L-type Ca2+ channel and link to insulin release. Am J Physiol Endocrinol Metab 289:E670-E677

22. Leitges M, Mayr M, Braun U et al (2001) Exacerbated vein graft arteriosclerosis in protein kinase Cdelta-null mice. J Clin Invest 108:1505-1512

23. Fielitz J, Kim MS, Shelton JM et al (2008) Requirement of protein kinase D1 for pathological cardiac remodeling. Proc Natl Acad Sci U S A 105:3059-3063

24. Fontes G, Zarrouki B, Hagman DK et al (2010) Glucolipotoxicity age-dependently impairs beta cell function in rats despite a marked increase in beta cell mass. Diabetologia 53:2369-2379

25. Briaud I, Harmon JS, Kelpe CL, Segu VB, Poitout V (2001) Lipotoxicity of the pancreatic beta-cell is associated with glucose-dependent esterification of fatty acids into neutral lipids. Diabetes 50:315-321

26. Wang Z, Thurmond DC (2009) Mechanisms of biphasic insulingranule exocytosis - roles of the cytoskeleton, small GTPases and SNARE proteins. J Cell Sci 122:893-903

27. Roduit R, Nolan C, Alarcon C et al (2004) A role for the malonyl$\mathrm{CoA} /$ long-chain acyl-CoA pathway of lipid signaling in the regulation of insulin secretion in response to both fuel and nonfuel stimuli. Diabetes 53:1007-1019
28. Kong KC, Butcher AJ, McWilliams P et al (2010) M3-muscarinic receptor promotes insulin release via receptor phosphorylation/ arrestin-dependent activation of protein kinase D1. Proc Natl Acad Sci U S A 107:21181-21186

29. Sumara G, Formentini I, Collins S et al (2009) Regulation of PKD by the MAPK p38delta in insulin secretion and glucose homeostasis. Cell 136:235-248

30. Rey O, Young SH, Cantrell D, Rozengurt E (2001) Rapid protein kinase $\mathrm{D}$ translocation in response to $\mathrm{G}$ protein-coupled receptor activation. Dependence on protein kinase C. J Biol Chem 276:32616-32626

31. Rybin VO, Guo J, Steinberg SF (2009) Protein kinase D1 autophosphorylation via distinct mechanisms at Ser744/Ser748 and Ser916. J Biol Chem 284:2332-2343

32. Tan M, Xu X, Ohba M, Ogawa W, Cui MZ (2003) Thrombin rapidly induces protein kinase $\mathrm{D}$ phosphorylation, and protein kinase $\mathrm{C}$ delta mediates the activation. J Biol Chem 278:2824-2828

33. Poitout V, Robertson RP (2008) Glucolipotoxicity: fuel excess and beta-cell dysfunction. Endocr Rev 29:351-366

34. Brownlie R, Mayers RM, Pierce JA, Marley AE, Smith DM (2008) The long-chain fatty acid receptor, GPR40, and glucolipotoxicity: investigations using GPR40-knockout mice. Biochem Soc Trans 36:950-954

35. Steneberg P, Rubins N, Bartoov-Shifman R, Walker MD, Edlund H (2005) The FFA receptor GPR40 links hyperinsulinemia, hepatic steatosis, and impaired glucose homeostasis in mouse. Cell Metab 1:245-258

36. Zawalich WS, Yamazaki H, Zawalich KC (2008) Biphasic insulin secretion from freshly isolated or cultured, perifused rodent islets: comparative studies with rats and mice. Metabolism 57:30-39

37. Wang Z, Oh E, Clapp DW, Chernoff J, Thurmond DC (2011) Inhibition or ablation of p21-activated kinase (PAK1) disrupts glucose homeostatic mechanisms in vivo. J Biol Chem 286:4135941367

38. Wang Z, Oh E, Thurmond DC (2007) Glucose-stimulated Cdc42 signaling is essential for the second phase of insulin secretion. J Biol Chem 282:9536-9546

39. Yashiro H, Tsujihata Y, Takeuchi K, Hazama M, Johnson PR, Rorsman P (2012) The effects of TAK-875, a selective G protein-coupled receptor 40/free fatty acid 1 agonist, on insulin and glucagon secretion in isolated rat and human islets. J Pharmacol Exp Ther 340:483-489

40. Zhao YF, Pei J, Chen C (2008) Activation of ATP-sensitive potassium channels in rat pancreatic beta-cells by linoleic acid through both intracellular metabolites and membrane receptor signalling pathway. J Endocrinol 198:533-540

41. Ullrich S, Pfleiderer M, Liebscher K, Katja F, Drews G, Christiansen E et al (2011) Effects of small FFA1 receptor agonists in insulin secreting cells. Diabetes 60(Suppl 1):2023, Abstract

42. Wang QJ (2006) PKD at the crossroads of DAG and PKC signaling. Trends Pharmacol Sci 27:317-323

43. Cantley J, Boslem E, Laybutt DR et al (2010) Deletion of protein kinase Cdelta in mice modulates stability of inflammatory genes and protects against cytokine-stimulated beta cell death in vitro and in vivo. Diabetologia 54:380-389

44. Carpenter L, Mitchell CJ, Xu ZZ, Poronnik P, Both GW, Biden TJ (2004) PKC alpha is activated but not required during glucoseinduced insulin secretion from rat pancreatic islets. Diabetes 53:53-60

45. Hennige AM, Ranta F, Heinzelmann I et al (2010) Overexpression of kinase-negative protein kinase Cdelta in pancreatic beta-cells protects mice from diet-induced glucose intolerance and beta-cell dysfunction. Diabetes 59:119-127

46. Waldron RT, Innamorati G, Torres-Marquez ME, Sinnett-Smith J, Rozengurt E (2012) Differential PKC-dependent and -independent 
PKD activation by $G$ protein alpha subunits of the Gq family: selective stimulation of PKD Ser autophosphorylation by Galphaq. Cell Signal 24:914-921

47. Pusapati GV, Eiseler T, Rykx A et al (2012) Protein kinase D regulates RhoA activity via rhotekin phosphorylation. J Biol Chem 287:9473-9483
48. Tomas A, Yermen B, Regazzi R, Pessin JE, Halban PA (2010) Regulation of insulin secretion by phosphatidylinositol-4,5bisphosphate. Traffic 11:123-137

49. Spratley SJ, Bastea LI, Doppler H, Mizuno K, Storz P (2011) Protein kinase D regulates cofilin activity through p21-activated kinase 4. J Biol Chem 286:34254-34261 